\title{
Mecenas en el siglo XXI: los casos de restauración y recuperación del patrimonio cultural valenciano: de San Nicolás a los Santos Juanes
}

\author{
Francisca Ramón Fernández | Dpto. de Urbanismo, Universitat Politècnica de València \\ URL de la contribución <www.iaph.es/revistaph/index.php/revistaph/article/view/4556>
}

Si hablamos de recuperación del patrimonio cultural valenciano inmediatamente surge el nombre de la Fundación Hortensia Herrero, que ha sido la artífice de diversas actuaciones para recuperar tanto las pinturas murales como las esculturas de la nave central de la Iglesia de San Pedro Mártir y San Nicolás Obispo, y que se conoce popularmente por el público como "La Capilla Sixtina Valenciana"; como también la actual recuperación de las pinturas al fresco de las bóvedas del templo de los Santos Juanes, obra de Palomino, ambas recuperaciones llevadas a cabo por la Universitat Politècnica de València bajo la dirección de la profesora catedrática Pilar Roig Picazo (ROIG PICAZO; BERNAL NAVARRO; REGIDOR ROS et ál., 2018).

Esta experiencia exitosa de mecenazgo que ha tenido una enorme repercusión social, y que ha supuesto una puesta en valor de nuestro patrimonio cultural nos hace plantearnos algunas cuestiones y reflexiones en torno a esta figura y el compromiso social para llevarlas a cabo. Se une la filantropía, así como la conocida frase "por amor al arte", pero también se une una falta de regulación a nivel estatal, más allá de la contemplación tributaria, que pueda precisar la implicación cultural de los mecenas de la modernidad.

En los dos casos mencionados (San Nicolás y Santos Juanes) a partir de la restauración, en el primer caso, y durante la restauración, en el segundo, se cobra entrada por contemplar la obra, fuera de las horas de culto, situación que provoca discrepancias entre la ciudadanía, especialmente en la residente. Actualmente se ha puesto en marcha un circuito, en el que se añade la visita al Colegio del Arte Mayor de la Seda, también restaurada por la mencionada Fundación, y que lleva a cabo una empresa que es la que gestiona culturalmente los tres espacios.

Nos podemos plantear si ello supone una operación de marketing aprovechando el impacto social que produjo la restauración en los ciudadanos. Consideramos que en los primeros momentos los espacios se podían visitar de forma libre y transcurrido un tiempo se implantó el cobro de una entrada para la visita, con un régimen diferente al establecido en otros espacios, como, por ejemplo, museos. Junto a ello, otro problema que se plantea es la "utilización" del espacio. En este caso, estamos hablando de espacios de culto, por lo que las actividades paralelas que se realizan están relacionadas con el carácter sacro del mismo (conciertos), pero se plantearía si es posible realizar otro tipo de actividades. Desde luego, podemos indicar el debate surgido con la utiliza-

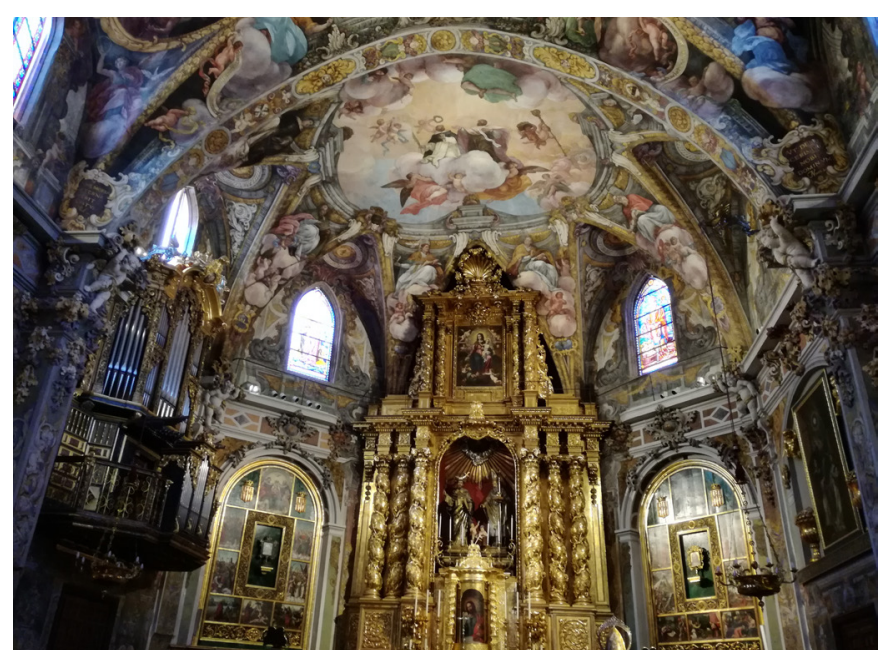

Interior de la Iglesia de San Pedro Mártir y San Nicolás Obispo | foto Elisa Marianini 
ción del The Metropolitan Museum of Art con la organización del evento benéfico de la gala para la recaudación de fondos del museo, y que se refleja en el documental The first monday in may. La pregunta sería ¿es lícita la obtención de fondos a través de dicha actividad ya que se está utilizando un espacio que es un museo? (RAMÓN FERNÁNDEZ; CABEDO MALLOL; CASAR FURIÓ et ál., 2019).

La figura del mecenas o filántropo no es moderna, ya que su origen se encuentra en la Roma clásica, adquiriendo todo su esplendor en el Renacimiento (RAMÓN FERNÁNDEZ, 2015: 246). Se tiende a hablar de mecenazgo como sinónimo de crowdfunding (GUTIÉRREZ RODRÍGUEZ, 2014), teniendo en cuenta que se contempla en la Ley 5/2015, de 27 de abril, de fomento de financiación empresarial, como plataforma de financiación participativa, e incluso estableciendo semejanzas con suscripción popular. Sin embargo, son figuras diferentes, y con un tratamiento jurídico distinto. De igual forma, hay que diferenciarlo del patrocinio (CANTÓ NAVÉS, 2019).

El mecenazgo en la actualidad tiene un repunte de auge, dado lo precario de los presupuestos públicos para cubrir los gastos del patrimonio cultural, la aportación privada resulta fundamental para solventar las carencias en diversos escenarios (por ejemplo, las universidades). El o la mecenas se convierte en un salvador de la cultura. De hecho el Instrumento de Ratificación del Convenio para la Salvaguardia del Patrimonio Arquitectónico de Europa de 1985 establece la promoción del desarrollo del mecenazgo (RAMÓN FERNÁNDEZ, 2015).

Es interesante destacar que a nivel foral y autonómico se ha legislado de forma reciente sobre mecenazgo cultural: a) Ley Foral 8/2014, de 16 de mayo, reguladora del mecenazgo cultural y de sus incentivos fiscales en la Comunidad Foral de Navarra; b) Ley 9/2014, de 29 de diciembre, de impulso de la actividad y del mecenazgo cultural en la Comunitat Valenciana; c) Ley 20/2018, de 25 de julio, del mecenazgo cultural, científico y deportivo no profesional en la Comunitat Valenciana; d) Ley

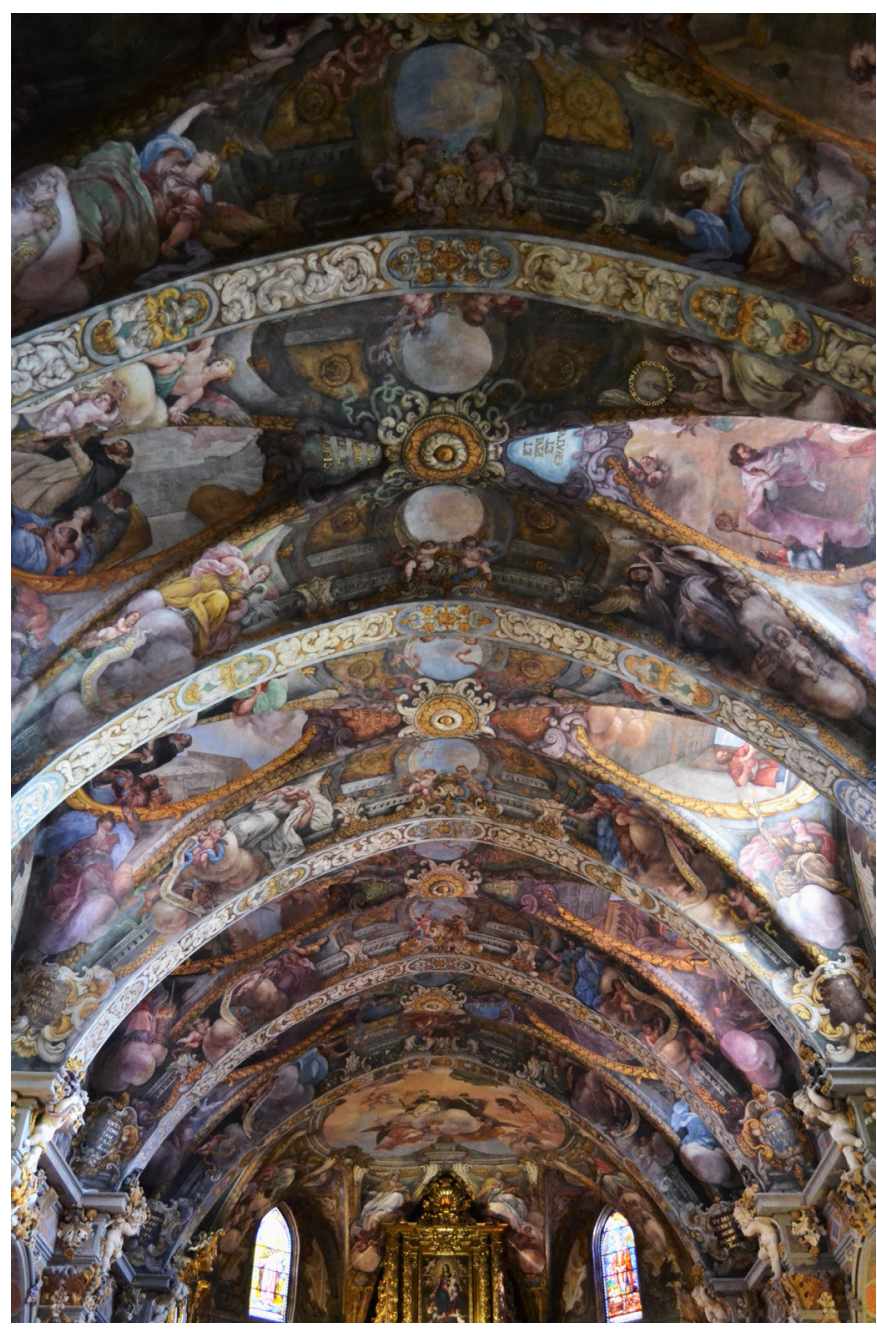

Pinturas al fresco de las bóvedas | foto Joanbanjo

$3 / 2015$, de 23 de marzo, por la que se regula el consumo cultural y el mecenazgo cultural, científico y de desarroIlo tecnológico, y se establecen medidas tributarias de la Comunidad Autónoma de las Illes Balears.

La regulación actual constituida por la Ley 49/2002, de 23 de diciembre, de régimen fiscal de las entidades sin fines lucrativos y de los incentivos fiscales al mecenazgo, y el Real Decreto 1270/2003, de 10 de octubre, por el que se aprueba el Reglamento para la aplicación del régimen fiscal de las entidades sin fines lucrativos y de los incentivos fiscales al mecenazgo, complementado 


\begin{abstract}
a debate Patrocinio, mecenazgo, crowdfunding ¿compromiso social o marketing interesado?
\end{abstract}
| coordina Ana Isabel Velasco Rebollo

por Ley 16/1985, de 25 de junio, del Patrimonio Histórico Español, no resulta suficiente, ya que se centra en los aspectos fiscales. Es necesaria una ley específica sobre mecenazgo, en la que se indiquen aspectos jurídicos y éticos, así como los límites respecto de las actividades a realizar.

No podemos obviar que la restauración, conservación y recuperación de los bienes (ya sean bienes de interés cultural o bienes de relevancia local) es competencia de los titulares, tanto de titularidad pública como privada, y que la ciudadanía debe adquirir un compromiso social por lo menos para coadyuvar a su conservación. Por ejemplo, podríamos indicar que una forma de conservación es la no depreciación de los bienes, esto es, un comportamiento ético en los casos en que se acceda a la contemplación del bien. Evitar actuaciones que afecten al bien en relación con no causarle un daño.

\section{BIBLIOGRAFÍA}

- CANTÓ NAVÉS, C. (2019) El patrocinio: Herramienta de márketing cada vez más preciada. Harvard Deusto Márketing y Ventas, n. ${ }^{0} 158,2019$, pp. 36-45

- GutiÉRREZ RODRígueZ, J. (2014) El "crowdfunding" mucho más que un mecenazgo. Contat4b/3, n. ${ }^{\circ} 44,2014$, pp. 10-11. Disponible en línea <https://dialnet.unirioja.es/servlet/ articulo?codigo $=4647477>$ [Consulta: 02/12/2019]

- INSTRUMENTO de Ratificación del Convenio para la Salvaguardia del Patrimonio Arquitectónico de Europa, hecho en Granada, el 3 de octubre de 1985. Boletín Oficial del Estado, n. ${ }^{\circ} 155$, de 30 de junio de 1989

- LEY 16/1985, de 25 de junio, del Patrimonio Histórico Español. Boletín Oficial del Estado, n. ${ }^{\circ}$ 155, de 29 de junio de 1985

- LEY 49/2002, de 23 de diciembre, de régimen fiscal de las entidades sin fines lucrativos y de los incentivos fiscales al mecenazgo. Boletín Oficial del Estado, n. ${ }^{\circ} 307$, de 24 de diciembre de 2002

- LEY FORAL 8/2014, de 16 de mayo, reguladora del mecenazgo cultural $y$ de sus incentivos fiscales en la Comunidad Foral de Navarra. Boletín Oficial del Estado, n. ${ }^{\circ}$ 137, de 6 de junio de 2014

- LEY 9/2014, de 29 de diciembre, de impulso de la actividad y del mecenazgo cultural en la Comunitat Valenciana. Boletín Oficial del Estado, n. ${ }^{\circ}$ 35, de 10 de febrero de 2015

- LEY 3/2015, de 23 de marzo, por la que se regula el consumo cultural y el mecenazgo cultural, científico y de desarrollo tecnológico, y se establecen medidas tributarias de la Comunidad Autónoma de las Illes Balears. Boletín Oficial del Estado, n. ${ }^{\circ}$ 96, de 22 de abril de 2015

- Ley $5 / 2015$, de 27 de abril, de fomento de financiación empresarial. Boletín Oficial del Estado, n. ${ }^{\circ} 101$, de 28 de abril de 2015

- LEY 20/2018, de 25 de julio, del mecenazgo cultural, científico y deportivo no profesional en la Comunitat Valenciana. Boletín Oficial del Estado, n. ${ }^{\circ}$ 223, de 14 de septiembre de 2018

- RAMÓN FERNÁNDEZ, F. (2015) Algunas cuestiones del mecenazgo y el patrimonio cultural. Revista Aranzadi de derecho patrimonial, n. ${ }^{\circ}$ 37, pp. 245-269

- RAMÓN FERNÁNDEZ, F.; CABEDO MALLOL, V.; CASAR FURIÓ, M. ${ }^{a}$ E.; GIMÉNEZ CHORNET, V.; LULL NOGUERA, C.; OLTRA GUTIÉRREZ, J. V.; SORIANO SOTO, M. ${ }^{a}$ D. (2019) El audiovisual The first Monday in may y su utilización como recurso para la mejora del aprendizaje. Puesta en valor y aplicación en el Máster en Gestión Cultural de la Universitat Politècnica de València. En IN-RED 2019. V Congreso de Innovación Educativa y Docencia en Red [en línea]. Valencia: Universitat Politècnica de València, 2019, pp. 1-10<http://ocs. editorial.upv.es/index.php/INRED/INRED2019/paper/viewFile/ 10544/4683> [Consulta: 03/12/2019]

- REAL DECRETO 1270/2003, de 10 de octubre, por el que se aprueba el Reglamento para la aplicación del régimen fiscal de las entidades sin fines lucrativos y de los incentivos fiscales al mecenazgo. Boletín Oficial del Estado, n. ${ }^{\circ} 254$, de 23 de octubre de 2003

- ROIG PICAZO, M. P.; BERNAL NAVARRO, J. C.; REGIDOR ROS, J. L.; BOSCH ROIG, L. (2018) Contextualización iconográfica e intervención en las pinturas murales de la Capilla de la Comunión de la Iglesia Parroquial de san Nicolás de Bari y de san Pedro Mártir en la ciudad de Valencia. Archivo de Arte Valenciano [en línea], XCIX, 2018, pp. 183-208<https://drive. google.com/file/d/1XntMLOxle3i15oXYomTa7hG0guEM5-Ue/ view> [Consulta: 03/12/2019] 